\title{
Impact of the Working Conditions on Health and Selected Job-related Diseases. An International Comparison
}

\author{
Daniela Hrehova ${ }^{1,{ }^{*}}$ and Pavel Ziaran ${ }^{2}$ \\ ${ }^{1}$ Technical University in Kosice, Dpt. of Social Sciences, Vysokoskolska 4, 04200 Kosice, Slovakia \\ ${ }^{2}$ University of Presov, Faculty of Management, Konstantinova 16, 08001 Presov, Slovakia
}

\begin{abstract}
.
Research background: The labor markets in the European countries are largely converging under the common platform of the EU legislation. However, the specific labor conditions across the countries still pertain, thus influencing the state of health differently across the countries.

Purpose of the article: The article has for objective to reveal the relations between labor conditions (job satisfactions, opportunity to develop, recognition for work, salary adequacy, freedom of decision-making, job stress and social support), on one hand, and the self-perceived state of health, number of chronic diseases and the occurrence of the selected job-related diseases (peptic ulcer, hypertension, heart attack), on the other. The comparison is carried out in the light of the cross-country comparison.

Methods: Sample consists of the employed and economically active employees, aged 50+, originating from $16 \mathrm{EU}$ countries, Switzerland and Israel $(\mathrm{N}=16713$ participants, females 53\%). The data are provided by the EU Share database (Survey of Health, Ageing and Retirement in Europe). We use ranking of countries by means (self-perceived state of health, number of chronic diseases) and the non-parametric regression analysis.

Findings \& Value added: All analyzed working conditions generate statistically significant relations with the self-perceived state of health at the all countries level. However, at the level of individual countries the patterns differ considerably (what rises methodological concerns on different country samples). As regards the specific diseases, considered as work-related: peptic ulcer is associated with all the working conditions analyzed, hypertension associates with four working factors and heart-attack with three. Findings bring important implications for the HR managers and relevant policy-makers.
\end{abstract}

Corresponding author: daniela.hrehova@tuke.sk 
Keywords: HR management; physical health; working conditions; EU countries comparison

JEL Classification: $M 54 ; 112 ; J 81$

\section{Introduction}

The question of physical health related to working conditions is of crucial importance. Globally, on the annual basis, social costs of to the work-related stress are estimated to range between 221 million and 187 billion USD; while $70-90 \%$ of the costs is attributed to the productivity losses [1].

Hereby presented text has for objective to provide same basic analysis of the relations between working conditions and physical health aspects in the sixteen EU countries Switzerland and Israel.

The relation between the working conditions and physical health is straightforward, mostly because of two reasons: (1) social and environmental factors can trigger various health problems and diseases, and (2) the routine type of activities performed regularly, bringing the same type of stress and strains can contribute to the health aggravation [2]. Since several decades, the working culture in many companies has incorporated habits of excessive working requirements for the employees, regular pressure to meet the deadlines, formally or informally expressed need to work overtime, etc. [3]. And subsequently, there is systematic evidence on the interconnection between unsatisfactory working atmosphere and the detrimental effects on physical and mental health of employees [4].

Good news is that managerial style focusing on the motivating aspects of the work performance (known as a promotion-focused job crafting) can improve the performance as well as the health state of employees [5].

\section{Literature review}

\subsection{Research from the point of view of working conditions}

Working conditions and atmosphere is complexly related to the health aspects. Research [6] on the group of educators showed the rank of occurrence of the stress-related diseases as follows: hypertension $(15,6 \%)$, peptic ulcer $(9,1 \%)$, asthma $(3,5 \%)$. Study further showed relations between the work-related aspects and specific diseases. Low job satisfaction and higher level of stress associate with a wide range of diseases as hypertension, heart diseases, peptic ulcer, lung diseases and risky behaviour. Stress combined with the lack of social support was related to hypertension, similarly as the poor prospects of the career advancement. Longitudinal research on the Australian population [7] brought following results: lack of the decision-making freedom relates to the increase of all-cause mortality $(39 \%)$. There was not a significant relation between the mortality and the job insecurity or unfair renumeration.

Job satisfaction belongs among the most widely analyzed work-related health aspects. Research [8] showed that job satisfaction relates to the level of self-perceived health. The findings also suggest that in the case of a low job satisfaction, reduced working hours might mitigate the health risks, what supports the trends in the flexible working hours contracts, especially in less satisfactory jobs. Study by [9] on the Chinese population migration from 
the rural to urban areas also confirmed negative relation between the job satisfaction and selfperceived state of health, both mental and physical.

Job stress usually appears in the situations where the excessive number of tasks are due in a short or limited time frame. A relatively large body of research is devoted to the analysis of impact of the combination of high working demands and lack of the decision-making latitude on wide range of health aspects of workers, both mental and physical. Later the aspect of the social support at work was added to the analytical frame. The combination of the three variables is usually denoted as the demand-control-support model, or Karasek's model [10]. Combination of the high working demands and low decision-making latitude is denoted as job strains. Meta-analysis measuring the relation between the mortality and the job strains confirmed the job strains significantly increase the mortality risk ratio; the risk was more accentuated for males [11].

\subsection{Research from the point of view of diseases (peptic ulcer, hypertension, heart attack)}

There is a systematic and substantial body of the research-based evidence on the relation between the peptic ulcer disease and working conditions, at the level of nation-wide studies as well as across the industries. According to the research [6], peptic ulcer relates to a wide spectrum of unsatisfactory working conditions as job stress, little freedom of decisionmaking, poor prospects of job advancement and job security.

The risk of the peptic ulcer incidence increases significantly with the stress expositions of employees; research [12] showed that peptic ulcer/stomach treatment incidence was 1,2\% in the high stress group and only $0,4 \%$ for a group exposed to low stressed. Research [13] showed also a strong relation between peptic ulcer and the lack of the social support at highly stress-exposed jobs.

A nation-wide research [14] on the South Korean population showed that the blue-collar workers were more affected by the peptic ulcer when compared to the white-collars; and independently from job status, adverse working conditions relate to the augmented risk of peptic ulcer.

Research show a strong relation between high job strains (according to the Karasek's model, combination of high working demands and low decision-making freedom) and the prevalence of hypertension; this tendency is more accentuated for males [15]. Research [16] also showed increased prevalence of hypertension relied to the blue-collar occupations (repair, maintenance, production). Research [17] showed that quick pauses between working shifts and consecutive night shifts contribute to the risk of hypertension.

Longitudinal large-scale research on French population [18] proved strong relation between the cardiovascular mortality and the broader range of job-related aspects as the lack of the decision-making freedom, lack of social support at work, job stress and excessive working demands. Using the meta-analysis, research [19] showed the lack of the decisionmaking latitude can increase the risk of mortality due to the coronary heart disease.

Interestingly, for the case of Swedish population, longitudinal research [20] did not confirm relation between the job strains and the cardiovascular mortality, instead education and conventional risky behaviors prevailed as CVD predictors. This might suggest, that if working conditions are in general favorable, supporting healthy working atmosphere and well-being and supporting working relations, the workplace does not augment the health risks.

Objective of this pilot explorative study is to reveal relations among the job satisfaction and selected conditions at the workplace and the selected aspects of physical health (using the data comprised in the database EU Share - Survey of Health, Ageing and Retirement in Europe). 


\section{Methodology}

We base our research on data from the database EU Share (Survey of Health, Ageing and Retirement in Europe). EU Share is a multidisciplinary international database containing microdata about health, socio-economic situation, social and family network of respondents over 50 years old. SHARE now covers majority of the European Union countries, Switzerland and Israel. In this research, we use the data from the wave no. 6 [21].

For the research purposes we selected participants who are still economically active, and their current economic status is defined as "employed" (in public sector, private sector, selfemployed). Total number of participants: 16.713 participants (females 53\%), average age (males: 63,4 SD 5,2 females: 61,9 SD 5,4). Representation by individual countries (see, tab. 1 , bellow).

We use data from the package Employment-Pension, containing data on self-reported aspects of perception labor conditions as follows:

1. Job satisfaction

2. Opportunity to develop new skills

3. Recognition for work

4. Salary is adequate

5. Social support at the workplace

6. Time pressure due to heavy workload

7. Little freedom to decide how to do the work

Variables are defined by the four-point Likert scale (1-strongly agree, 4-strongly disagree). Further we use the data from the package Physical Health, including following information: self-reported state of health ( 1 - excellent, 5 - poor), occurrence of the following diseases (peptic ulcer, hypertension, and heart attack).

We used analysis of means and non-parametric correlations (Spearman, Kendall Tau). As a first step we compare the quality of health at the level of individual countries, on the basis of the self-perceived health and the number of chronic diseases. Subsequently we will analyze relations among the conditions at the work-place and the self-perceived state of health at both levels, individual countries and all the countries in the data set (Spearman coefficient). As a third step we will analyze relations among the occurrence of the selected work-related diseases and the working conditions (Kendall Tau coefficient), at the level of the whole dataset.

Our original intention was to carry out an analysis based on the multiple regression models. However, both multiple linear regression model and ordinal logit model reported the social support as statistically insignificant, also with adjustment for gender; what is a contrary to the empirical expectations as well as to a numerous body of research. Subsequently, we restricted our methodology to correlation analysis, which provides more empirically consistent results.

\section{Results}

As a first step in the analysis we compare the quality of health at the level of individual states (tab. 1), on the basis of self-perceived state of health (mean value) and the number of chronic diseases (mean value). Among the top 3 countries with the most favorable self-perceived state of health belong Denmark, Sweden and Greece. As regards the number of chronic diseases, the most favorable results are seen in Switzerland, Italy and Croatia. At the less favorable bottom part of the table we find following countries: the self-perceived state of health (Poland, Portugal and Estonia), number of chronic diseases (Estonia, Czech Republic and Portugal). 
Table 1 Country ranking - self-perceived health (sorted by mean), number of chronic diseases (sorted by mean)

\begin{tabular}{|l|c|c|}
\hline \multicolumn{3}{|c|}{$\begin{array}{c}\text { Self-perceived state of health (1- } \\
\text { excellent, 5 - poor) }\end{array}$} \\
\hline Country & N valid & Mean \\
\hline Denmark & 1565 & 2,12 \\
\hline Sweden & 1036 & 2,35 \\
\hline Greece & 1072 & 2,36 \\
\hline Israel & 534 & 2,42 \\
\hline Switzerland & 946 & 2,43 \\
\hline Austria & 525 & 2,44 \\
\hline Belgium & 1557 & 2,59 \\
\hline Croatia & 493 & 2,59 \\
\hline Luxembourg & 367 & 2,61 \\
\hline France & 926 & 2,73 \\
\hline Spain & 1037 & 2,74 \\
\hline Slovenia & 655 & 2,75 \\
\hline Italy & 1198 & 2,75 \\
\hline CZ & 879 & 2,82 \\
\hline Germany & 1442 & 2,89 \\
\hline Poland & 376 & 3,06 \\
\hline Portugal & 260 & 3,30 \\
\hline Estonia & 1844 & 3,36 \\
\hline
\end{tabular}

\begin{tabular}{|l|c|c|}
\hline \multicolumn{3}{|c|}{ Number of chronic diseases } \\
\hline \multicolumn{1}{|c|}{ Country } & N valid & Mean \\
\hline Switzerland & 946 & 0,80 \\
\hline Italy & 1198 & 0,81 \\
\hline Croatia & 493 & 0,84 \\
\hline Austria & 524 & 0,85 \\
\hline Greece & 1072 & 0,87 \\
\hline Sweden & 1036 & 0,88 \\
\hline France & 927 & 0,95 \\
\hline Israel & 534 & 0,97 \\
\hline Slovenia & 655 & 0,98 \\
\hline Denmark & 1565 & 0,99 \\
\hline Spain & 1038 & 1,00 \\
\hline Poland & 376 & 1,07 \\
\hline Belgium & 1557 & 1,16 \\
\hline Luxembourg & 367 & 1,16 \\
\hline Germany & 1442 & 1,18 \\
\hline Estonia & 1840 & 1,20 \\
\hline CZ & 880 & 1,22 \\
\hline Portugal & 260 & 1,61 \\
\hline
\end{tabular}

In the following section we proceed with the analysis of the relation among the working conditions and the self-perceived state of health (tab. 2). Analysis is carried out at the level of individual countries as well as at the level of at the level of the whole dataset.

Table 2 Relation between the working conditions and the self-perceived state of health, at the level of individual countries and all countries (Spearman coefficients), ${ }^{*} \mathrm{p}<0,05$

\begin{tabular}{|c|c|c|c|c|c|c|c|}
\hline $\begin{array}{l}\hat{E} \\
\text { 吾 }\end{array}$ & 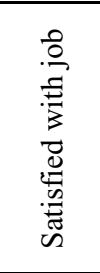 & 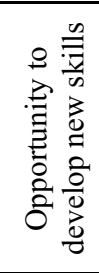 & 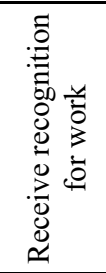 & 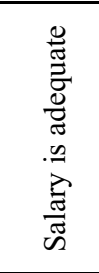 & 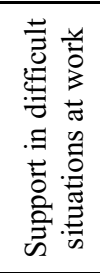 & 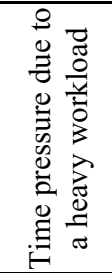 & 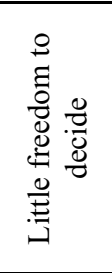 \\
\hline Austria & $0,134 *$ & $0,174 *$ & $0,172 *$ & $0,146^{*}$ & 0,066 & 0,031 & $-0,047$ \\
\hline Belgium & $0,222 *$ & $0,136 *$ & $0,135 *$ & $0,119 *$ & 0,096* & $-0,077^{*}$ & $-0,128 *$ \\
\hline Switzerland & $0,109 *$ & 0,046 & 0,060 & $0,116^{*}$ & $0,085 *$ & $-0,050$ & $-0,097^{*}$ \\
\hline $\mathbf{C Z}$ & $0,115 *$ & 0,121 * & $0,127 *$ & $0,125^{*}$ & $0,110 *$ & $-0,076^{*}$ & $-0,141^{*}$ \\
\hline Germany & $0,107 *$ & $0,113^{*}$ & $0,116^{*}$ & $0,116 *$ & $0,084 *$ & $-0,093^{*}$ & $-0,123^{*}$ \\
\hline Denmark & $0,184 *$ & $0,151^{*}$ & $0,105^{*}$ & 0,044 & $0,111^{*}$ & $-0,071^{*}$ & $-0,076^{*}$ \\
\hline
\end{tabular}




\begin{tabular}{|c|c|c|c|c|c|c|c|}
\hline \multirow{2}{*}{ Estonia } & \multirow{2}{*}{$0,141^{*}$} & \multirow{2}{*}{$0,231 *$} & \multirow{2}{*}{$0,116^{*}$} & \multirow{2}{*}{$0,111^{*}$} & \multirow{2}{*}{$0,106^{*}$} & \\
\hline & & & & & & $-0,026$ & $-0,090^{*}$ \\
\hline Spain & $0,177^{*}$ & 0,139* & 0,128* & 0,110* & 0,133* & $-0,066^{*}$ & $-0,006$ \\
\hline France & $0,128 *$ & $0,158^{*}$ & $0,138^{*}$ & 0,074 & 0,071 & $-0,075$ & $-0,066$ \\
\hline Greece & $0,126^{*}$ & 0,066 & 0,083 & 0,158* & $-0,015$ & $-0,014$ & $-0,060$ \\
\hline Israel & 0,047 & $0,088^{*}$ & $-0,023$ & $0,149 *$ & 0,019 & 0,083 & 0,024 \\
\hline Italy & $0,167 *$ & $0,182 *$ & $0,116^{*}$ & $0,127 *$ & $0,111^{*}$ & $-0,012$ & $-0,066$ \\
\hline Luxembourg & $0,132 *$ & $0,318^{*}$ & $0,182 *$ & $0,159 *$ & $0,156^{*}$ & $-0,190^{*}$ & $-0,112$ \\
\hline Poland & 0,011 & 0,170 & 0,065 & 0,122 & 0,160 & $-0,035$ & 0,001 \\
\hline Portugal & 0,121 & $0,216^{*}$ & 0,069 & $0,184^{*}$ & 0,139 & $-0,178^{*}$ & $-0,089$ \\
\hline Sweden & $0,155^{*}$ & $0,095 *$ & $0,137 *$ & $0,146 *$ & $0,164 *$ & $-0,068^{*}$ & $-0,100^{*}$ \\
\hline Slovenia & $0,168 *$ & $0,155^{*}$ & $0,122^{*}$ & $0,146^{*}$ & $0,131 *$ & $-0,103^{*}$ & $-0,118$ \\
\hline $\begin{array}{l}\text { ALL } \\
\text { COUNTRIES }\end{array}$ & $0,162 *$ & $0,141 *$ & $0,133 *$ & $0,165^{*}$ & $0,087^{*}$ & $-0,022 *$ & $-0,112$ \\
\hline
\end{tabular}

At the level of individual countries, it is interesting to note that each country provide different correlation coefficients (tab. 2, column/variable); however the general trends are noticeable between the particular working conditions and the self-perceived state of health. At the level of all countries, we found correlation coefficients, all statistically significant at the level $\mathrm{p}<0,05$ as follows: job satisfaction $(0,162)$, opportunity to develop new skills $(0,141)$, recognition for work $(0,133)$, adequate salary $(0,165)$, social support $(-0,022)$, lack of decision-making freedom $(-0,112)$.

Following sections brings results on the analysis between the selected work-related diseases and the working conditions, at the level of all countries (tab. 3); correlations are significant at the level $p<0,01$. We observe that in the case of peptic ulcer disease, there are significant correlations for all the working conditions, with the correlation coefficient ranging, in absolute value, from 0,02 to 0,04 . 
Table 3 Relation between the working conditions and the occurrence of selected work-related diseases (Kendall Tau coefficient), ${ }^{* *} \mathrm{p}<0,01$

\begin{tabular}{|c|c|c|c|}
\hline & 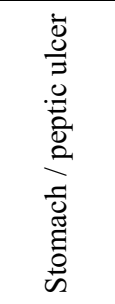 & 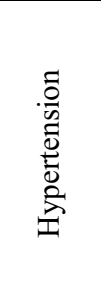 & 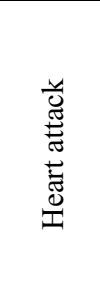 \\
\hline Satisfied with (main) job & $0,04 * *$ & $\mathbf{0 , 0 2 * *}$ & 0,01 \\
\hline Opportunity to develop new skills in (main) job & $\mathbf{0 , 0 3} * *$ & $\mathbf{0 , 0 3} * *$ & $\mathbf{0 , 0 2} * *$ \\
\hline Salary or earnings are adequate in (main) job & $\mathbf{0 , 0 3 * *}$ & $\mathbf{0 , 0 3} * *$ & $0,02 * *$ \\
\hline Receive recognition for work in (main) job & $\mathbf{0 , 0 3 * *}$ & $\mathbf{0 , 0 2} * *$ & 0,01 \\
\hline Receive support in difficult situations at work & $0,04 * *$ & 0,01 & $0,02 * *$ \\
\hline Time pressure due to a heavy workload & $-0,03 * *$ & 0,01 & 0,01 \\
\hline Little freedom to decide & $-0,02 * *$ & $-0,01$ & 0,01 \\
\hline
\end{tabular}

For hypertension we see four statistically significant relations at four working conditions: job satisfaction $(0,02)$, opportunity to develop new skills $(0,03)$, adequate salary $(0,03)$ and the recognition for work $(0,02)$. For the case of heart attack there are three statistically significant relations: opportunity to develop new skills $(0,02)$, adequate salary $(0,03)$, social support $(0,02)$.

\section{Discussion}

In the first part of our research we created a rank of countries based on the self-perceived state of health and the number of chronic diseases. Among the countries with the most favorable results belong Denmark, Sweden, Greece as regards self-perceived state of health, Switzerland, Italy and Croatia when it comes to the chronic diseases. Countries at the bottom part of the rank are Portugal, Estonia, Poland and Czech Republic.

According to the European health index proposed by [22], following countries are on the top positions: Netherlands, Denmark, Sweden and Ireland. At the less favorable part of ranking find their place: Estonia, Lithuania, Poland and Bulgaria. To certain extent those results correspond to our findings. (The proposed health index is based on working conditions, general state of health, health system, quality of life, mental health, drug abuse and risk health factors.)

Job satisfaction belongs among the most analyzed work-health related aspects. Our research showed an important relation between the job satisfaction and the self-perceived state of health what corresponds to other researches $[2,8,9]$.

System of rewards (formal and informal appreciation) is closely related to the job satisfaction $[23,24]$. Our result show that aspects which are pillars of the reward system 
(recognition for work, salary adequacy, opportunity to develop) affect significantly the selfperceived state of health.

An important body of research is devoted to the impact of the triad of working conditions (social support, decision-making freedom and job stress) known as Karasek's model on health and well-being [10,11]. Our findings confirm the impact of the triad on physical health. The impact of the lack of social support and job stress corresponds to the general empirical expectations. The impact of the decision-making freedom on health is less intuitively evident, however our results show this aspect belongs among the most healthimpactful, what corresponds to other longitudinal researches [7].

As regards the research related to Karasek's model [10,11], it is rather surprising to note that the social support and the time pressure due to a heavy workload come out as the least important aspects when compared to other working condition factors (tab. 2, bottom line, all countries).

Final section of the research reveals the relation between the working conditions and selected work-related diseases. Our results show that peptic ulcer is associated (at the level of significance $\mathrm{p}<0,01$ ) with all seven working conditions we tested. This makes the peptic ulcer one of the most common diseases caused by the multiple working conditions, what corresponds also to research [6]. According to [13], risk of the peptic ulcer disease connects with social support; in our research the correlation coefficient between the lack of social support and the peptic ulcer occurrence is the highest, together with the low job satisfaction (tab. 3). Similarly, as suggest research [12], our research confirms peptic ulcer relation with stressful working conditions (tab. 3).

Our findings confirm relations among the hypertension incidence and four working conditions (job satisfaction, opportunity to develop, adequacy of salary and job recognition). On the other hand, quite surprisingly, when compared to the research $[11,15]$, we did not confirm the relation among the hypertension and three variables forming the Karasek's model (social support, decision-making latitude and job stress).

As regards the risk of heart attack we found three variables generating a statistically significant relation (opportunity to develop, salary adequacy, social support). Similarly, as for the case of hypertension (with the exception of social support), we do not find the relation with the variables forming the Karasek's model, unlike the research [18].

Finally, there are two methodological notes to make: (1) If the research concerns the workers/employees who have already gastric/duodenal, there is a significant relation with the adverse working conditions [14]. On the other hand, if the subjects of research are workers/employees who face adverse/stressful working conditions, the relation with the peptic ulcer might not be always significant [23]; evidently due to a more complex disease etiology and possible specificity of the sample. This knowledge might apply analogically to other variables and research designs. (2) Our research show that different samples (different countries) might provide sometimes quite different results (tab. 2, different correlation coefficients for one variable/column in various countries). This rises a crucial methodological concern and opens following questions: Is the difference caused by the real difference in the state of health in the respective countries, or by the different approach in sampling, or perhaps differences in cultural perception of the questionnaire in the various language version? The concern is accentuated by the fact that the EU Share dataset was created with the ambition to be robust and representative.

\section{Conclusion}

This research contributes to a wide body of the global research effort of the academic community, trying to bring an evidence on the crucial importance of the quality of working conditions and atmosphere on the essential state of health. The fact that our results are based 
on the sample of 16.713 people (economically active, age above 50, covering $16 \mathrm{EU}$ countries, plus Switzerland and Israel), gives the weights to our findings regarding the impact of working conditions on health.

Our research shows that basically each and every aspect of the working conditions \& atmosphere has impact on the health quality, should it be general state of health or diseases, considered as job-related.

The corporate culture based on the excessive working demands, tough deadlines and targets, combined with the lack of the decision-making freedom and adverse social atmosphere is undoubtedly a significant health risk factor. Furthermore, not well-thought design of the motivational systems based on financial and non-financial benefits, associated with lower job satisfaction can work as a direct cause of health aggravation and consecutive job-related diseases.

However, the good news is that well-designed working culture and micro-management, built on the principles respecting employees' well-being, can eliminate or at least reduce the risk of work-related diseases. We believe, this research might bring a value for HR managers as well as for the policy makers in the relevant areas.

Further research might shed more light on the subtle aspects of the work-related health risks. And especially data based on the EU Share platform (Survey of Health, Ageing and Retirement in Europe) can be very useful in this research effort.

\section{References}

1. Hassard, J., Teoh, K. R., Visockaite, G., Dewe, P., \& Cox, T. (2018). The cost of workrelated stress to society: A systematic review. Journal of Occupational Health Psychology, 23(1), 1-17.

2. Faragher, E. B., Cass, M., \& Cooper, C. L. (2013). The relationship between job satisfaction and health: a meta-analysis. In From Stress to Wellbeing Volume 1 (pp. 254271). Palgrave Macmillan, London.

3. Paoli, P. (1992). First European survey on the work environment 1991-1992. European Foundation for the improvement of living and working conditions.

4. Kenny D.T., Carlson J.G., McGuigan F.J., et al (2003). Stress and health: research and clinical applications. Amsterdam: Harwood Academic Publishers, 2000.

5. Lichtenthaler, P. W., \& Fischbach, A. (2019). A meta-analysis on promotion-and prevention-focused job crafting. European Journal of Work and Organizational Psychology, 28(1), 30-50.

6. Peltzer, K., Shisana, O., Zuma, K., Van Wyk, B., \& Zungu-Dirwayi, N. (2009). Job stress, job satisfaction and stress-related illnesses among South African educators. Stress and Health. Journal of the International Society for the Investigation of Stress, 25(3), 247-257.

7. Taouk, Y., LaMontagne, A. D., Spittal, M. J., \& Milner, A. (2020). Psychosocial work stressors and risk of mortality in Australia: analysis of data from the Household, Income and Labour Dynamics in Australia survey. Occupational and Environmental Medicine, 77(4), 256-264.

8. Bartoll, X., \& Ramos, R. (2020). Worked hours, job satisfaction and self-perceived health. Journal of Economic Studies.

9. Liang, D., \& Xu, D. (2020). Health-related quality of life in Chinese rural-to-urban migrants: Investigating the roles of working conditions and job satisfaction. Journal of Community Psychology, 48(8), 2663-2677. 
10. Theorell, T. (2020). The Demand Control Support Work Stress Model. Handbook of Socioeconomic Determinants of Occupational Health: From Macro-level to Micro-level Evidence, 1-15.

11. Amiri, S., \& Behnezhad, S. (2020). Job strain and mortality ratio: a systematic review and meta-analysis of cohort studies. Public Health, 181, 24-33.

12. Deding, U., Ejlskov, L., Grabas, M. P. K., Nielsen, B. J., Torp-Pedersen, C., \& Bøggild, H. (2016). Perceived stress as a risk factor for peptic ulcers: a register-based cohort study. BMC gastroenterology, 16(1), 140.

13. Lin, P. Y., Wang, J. Y., Shih, D. P., Kuo, H. W., \& Liang, W. M. (2019). The interaction effects of burnout and job support on peptic ulcer disease (PUD) among firefighters and policemen. International Journal of Environmental Research and Public Health, 16(13), 2369.

14. Choi, Y. I., Chung, J. W., Kim, K. O., Kwon, K. A., Kim, Y. J., \& Park, D. K. (2020). Effect of work-related factors on the prevalence of peptic ulcer disease among Korean workers: a nationwide population-based study. International Archives of Occupational and Environmental Health, 93, 965-973.

15. Lavigne-Robichaud, M., Trudel, X., Duchaine, C. S., Milot, A., Gilbert-Ouimet, M., Vézina, M., ... \& Brisson, C. (2019). Job strain and the prevalence of uncontrolled hypertension among white-collar workers. Hypertension Research, 42(10), 1616-1623.

16. Mendy, V. L., Vargas, R., Ogungbe, O., \& Zhang, L. (2020). Hypertension among Mississippi Workers by Sociodemographic Characteristics and Occupation, Behavioral Risk Factor Surveillance System. International Journal of Hypertension, 2020.

17. Cho, Y. S., Lee, S., Yoon, J. H., Lee, J., Park, J. B., Lee, K. J., \& Jeong, I. (2020). Short rest between shifts and risk of hypertension in hospital workers. Journal of Hypertension, 38(2), 211-217.

18. Niedhammer, I., Milner, A., Geoffroy-Perez, B., Coutrot, T., LaMontagne, A. D., \& Chastang, J. F. (2020). Psychosocial work exposures of the job strain model and cardiovascular mortality in France: results from the STRESSJEM prospective study. Scandinavian Journal of Work, Environment \& Health, 46(5), 542-551.

19. Taouk, Y., Spittal, M. J., LaMontagne, A. D., \& Milner, A. J. (2020). Psychosocial work stressors and risk of all-cause and coronary heart disease mortality: A systematic review and meta-analysis. Scandinavian Journal of Work, Environment \& Health, 46(1), 19-31.

20. Padyab, M., Blomstedt, Y., \& Norberg, M. (2014). No association found between cardiovascular mortality, and job demands and decision latitude: Experience from the Västerbotten Intervention Programme in Sweden. Social Science \& Medicine, 117, 5866.

21. Börsch-Supan, A. (2017). Survey of Health, Ageing and Retirement in Europe (SHARE) Wave 6. Release version: 6.0. 0. SHARE-ERIC, editor.

22. Fernandez-Crehuet, J. M., Rosales-Salas, J., \& de Ramos, S. (2019). State of health in the European Union: A European health index. Journal of Healthcare Quality Research, 34(6), 308-313.

23. Lihm, H. S., Park, S. H., Gong, E. H., Choi, J. S., \& Kim, J. W. (2012). Relationship between occupational stress and gastric disease in male workers. Korean Journal of Family Medicine, 33(5), 311.

24. Pfister, I. B., Jacobshagen, N., Kälin, W., \& Semmer, N. K. (2020). How does appreciation lead to higher job satisfaction?. Journal of Managerial Psychology, 35(6), 465-479. 